Father's Parenting Stress after the Arrival of a New Child

Chris Knoester and Richard Petts

Ohio State University

Richard J. Petts

Ball State University

Author Note

Chris Knoester, Department of Sociology, Ohio State University; Richard J. Petts, Department of Sociology, Ball State University.

Correspondence concerning this article should be addressed to Chris Knoester, Department of Sociology, Ohio State University, 152 Townshend Hall 1885 Neil Ave., Columbus, OH 43210. E-mail: knoester.1@osu.edu

** This is the peer reviewed version of the following article:

Knoester, Chris, and Richard J. Petts. 2017. "Parenting Stress among Disadvantaged Fathers.” Family Relations 66:367-382.

which has been published in final form at https://doi.org/10.1111/fare.12263

This article may be used for non-commercial purposes in accordance with Wiley Terms and Conditions for Use of Self-Archived Versions. 


\begin{abstract}
Objective: This study analyzed the relationship between father identity characteristics and father's parenting stress over the first five years after a birth.

Background: Previous work has considered how father identities shape father involvement, but has not focused on parenting stress. Understanding parenting stress is important as it is linked to fathers' and children's well-being.
\end{abstract}

Method: We analyzed Fragile Families (FFCW) data $(\mathrm{N}=2,547)$, using OLS and fixed-effects analyses. The FFCW follows the families of a cohort of new children who were born in large urban areas of the U.S., in the late 1990s.

Results: OLS results indicated that positive attitudes about fatherhood, wanting to provide direct care, and having higher levels of support from the birth mother predicted lower levels of father's parenting stress one year after a birth; father engagement, changes in birth mother's support, and inconsistent financial support were also significantly associated with parenting stress. Fixed effects results indicated that changes in father engagement were negatively associated with changes in father's parenting stress over years 1-5; changes in father's inconsistent financial support were positively associated with parenting stress. Finally, we found evidence that father identity characteristics moderate predictors of parenting stress.

Conclusion: Father identities seem to play an important role in shaping fathering experiences and father's parenting stress.

Implications: Fathers should be encouraged and supported in developing more salient father identities and fathering commitments by significant others, family practitioners, and public policies.

Keywords: fatherhood, father identity, fathering, parenting, parenting stress 


\section{Father's Parenting Stress after the Arrival of a New Child}

Fatherhood experiences have been notably changing as a result of expanded expectations for fathering, increased diversity in family structures, and heightened levels of socioeconomic inequalities across families. Expectations for responsible fathering have shifted toward fathers having stronger emotional connections to their children, being more engaged in children's lives, and assuming more egalitarian family roles — while still fulfilling the tradition role of providing a comfortable level of financial support. Yet, fathers have unevenly fulfilled these expectations (Doherty, Kouneski, \& Erickson, 1998; Pleck \& Masciadrelli, 2003). Structurally, fatherhood contexts - that is, the settings in which men father-have become more varied due to increases in nonmarital fertility, cohabitation, and relationship instability among parents (McLanahan, 2004; Tach, Mincy, \& Edin, 2010). Furthermore, fathering responsibilities have often been passed off after the dissolution of a dating, marital, or cohabiting relationship that involves children (Furstenberg \& Cherlin, 1991; Tach et al., 2010). Fatherhood contexts have also become stunningly disparate in the amount of human capital, stability, social support, and relationship quality that is present in them — contributing to diverging destinies in family wellbeing (Marsiglio \& Roy, 2012; McLanahan, 2004).

Nonetheless, research has rarely studied how fathers view their parenting experiences. In addition, there has been little evidence produced about the factors that encourage fathers to have more positive, versus more negative, parenting experiences (Bronte-Tinkew, Moore, Matthews, \& Carrano, 2007; Bronte-Tinkew, Horowitz, \& Carrano, 2010). Instead, fatherhood research has been focused on describing, predicting, and considering the effects of father involvementespecially as it pertains to children's outcomes. Comparatively little research has considered the 
effects of fatherhood on men's identities, family contexts, and feelings of well-being (Marsiglio, Amato, Day, \& Lamb, 2000; Marsiglio \& Roy, 2012; Pleck \& Masciadrelli, 2003).

In this study, we sought to better understand fathers' interest, preparation, and reactions to the arrival of a new child. We focused on analyzing the extent to which father identity characteristics predicted parenting stress among fathers. Father identity characteristics included indicators of the salience of father's parenting role identity, behavioral commitments that enable relationships with one's child, and family supports that shape father identities.

Parenting stress has been an important and understudied indicator of well-being. By definition, parenting stress demonstrates evidence that parenting demands exceed one's ability to comfortably meet those demands. It has been linked to father's health and well-being, and has also predicted parenting practices and child development, yet little is known about its patterns, causes, and consequences (Abidin, 1992; Bronte-Tinkew et al., 2007; 2010; Nomaguchi \& Johnson, 2014). Expanded expectations for fathering, more diverse family structures, and more unequal levels of human and social capital among fathers may have led to particularly high levels of parenting stress.

The purpose of this study was twofold. First, we analyzed the extent to which father identity characteristics predicted father's parenting stress one year after the arrival of a new child. This was an attempt to understand how father identities and the situational context at birth may lead to differing levels of father's parenting stress one year later.

Second, we investigate how father identity characteristics may shape changes in parenting stress within individual fathers. By focusing on the extent to which changes in father identity characteristics predicted changes in parenting stress, these fixed-effects analyses allowed us to become more confident about the potential causes of parenting stress. Fixed effects control 
for any observed or unobserved heterogeneity in the stable characteristics of individuals and provide stronger evidence about whether selection into relationship statuses or initial levels of fathering behaviors might be driving statistical associations (Allison, 2009). The emphasis of this investigation was necessarily on time-varying characteristics of fathers, however.

Although recent qualitative research (e.g., Edin \& Nelson, 2013; Marsiglio \& Roy, 2012) has described the processes of forming, enacting, and modifying father identities, and the implications of these identities for fathering behaviors and some feelings of well-being, researchers have not quantitatively considered how father identities may color fathers' views of their parenting experiences. Father identities may encourage involvement that benefits children and their mothers (Ihinger-Tallman, Pasley, \& Buehler, 1993; Marsiglio \& Roy, 2012). Enabling salient, committed, and supported father identities may also help to reduce parenting stress as fathers become better positioned to embrace fathering responsibilities.

The present study also moved beyond previous research that has focused largely on resident and relatively affluent fathers. We considered predictors of parenting stress within a sample of disadvantaged fathers from the Fragile Families and Child Wellbeing Study. Relative to the fathers typically included in research, parents in this study were less likely to be married to one another, less likely to live with one another, more likely to struggle with economic strains, less likely to have excess human capital to draw upon, more likely to be young parents, and were disproportionately members of racial-ethnic minority groups. In this context, the challenges of embracing, obtaining support for pursuing, and fulfilling the so-called "new fatherhood" ideal— where men are expected to be competent contributors to their families via the labor market as well as through direct caretaking and positive engagement activities in the home-were more profound. Also, the risks for parenting stress, and any consequences that may derive from it, 
were great (Bronte-Tinkew et al., 2010; McLanahan \& Carlson, 2003; Nomaguchi \& Johnson, 2014).

\section{Conceptual Framework}

The conceptual framework for our study recognized that parenthood is challenging and frequently leads to stress (Evenson \& Simon, 2005; Umberson, 2010). Specifically, we integrated identity theory (Ihinger-Tallman et al., 1993; Rane \& McBride, 2000; Stryker, 1968) with Abidin's (1990; 1992) model of parenting stress to frame our analysis. Identity theory captures the focus for our study and led to hypotheses about the relationships between father identity indicators and parenting stress. Abidin's model of parenting stress theoretically grounded our understanding of the predictors of parenting stress and directed the inclusion of father-specific, coparenting, and child-specific covariates.

\section{Father Identity Characteristics}

Identity theory has been frequently used to understand the motivation for, and consequences of, fathering behaviors. Through interactive socialization processes, opportunity, and self-reflection, fathers actively develop parenting role identities - their sense of what the status and roles of being a father means to them. The salience of father identities, commitments to enable relationships with children, and the extent to which identities are supported are key tenets of a father identity perspective (Ihinger-Tallman et al., 1993; Marsiglio, 1994; Marsiglio \& Roy, 2012; Rane \& McBride, 2000; Stryker, 1968). The beliefs, actions, and social interactions that are part of these tenets may also have implications for father's parenting stress (Knoester, Petts, \& Eggebeen, 2007). We considered a father's beliefs and prenatal actions to be indicative of the salience of his father identity when his new child arrived. After the child's birth, we considered a father's engagement with his child(ren) and provision of financial support to 
represent his commitments to enable relationships with his child(ren). We considered evidence of support from the birth mother and having had an involved father to reflect the extent to which significant others encouraged the formation of a father's parenting role identity.

Salience of father identities. The salience of father identities refers to their perceived importance relative to other identities. Following Ihinger-Tallman et al. (1993), we assumed that fathers with more salient father identities were especially likely to value the statuses and roles of fatherhood. For example, they were expected to be more likely to express positive attitudes about fatherhood, yearn to provide direct care for their children, and be involved in preparing for their child's birth, compared to fathers with less salient father identities. We anticipated that if fathers had more positive attitudes about their status and roles as a parent, they would be less likely to become aggravated by parenting. In fact, indicators of father identity salience may interact such that parenting stress may become especially low when fathers possess particularly salient father identities. The salience of parenting role identities may also moderate associations between parenting-relevant stressors and parenting stress (Abidin, 1992; Rane \& McBride, 2000). For example, more salient father identities may buffer associations between parentingrelevant stressors and feelings of parenting stress.

Commitment to others. Commitment to others is another central aspect of identity theory. Commitment to others entails behavioral choices that are expected to flow from a father's parenting identity and the salience of that identity, although commitments to these actions may also reshape parenting role identities. We focused on commitments that enable relationships with one's child(ren), such as being engaged with one's child and providing financial support (Ihinger-Tallman et al, 1993; Marsiglio, 1994; Stryker, 1968). 
On the one hand, fathers who make commitments to enable relationships with their child(ren) may experience relatively low levels of parenting stress because they are fulfilling the expected roles of fathering. They may also enjoy the relationships and interactions that result from their fathering behaviors. On the other hand, fathers who make commitments to enable relationships with their child may consequently experience more parenting stress because of the elevated work levels inherent in a father's involvement and financial support. Some evidence has supported the former argument, suggesting that more involved fathers and fathers who provided financial support for their children were more likely to experience increases in their feelings of well-being after the arrival of a new child (Bronte-Tinkew et al., 2010; Knoester et al, 2007; Schindler, 2010). In fact, these commitments may interact with one another in predicting father's parenting stress such that fathers may have especially low levels of parenting stress when they are highly engaged with their child and provide financial support. Because commitments that enable relationships with one's children fulfill common parenting responsibilities, it may be that enacting such commitments may also buffer the association between parenting-relevant stressors and parenting stress.

Importance of significant others. Finally, identity theory recognizes the importance of significant others for identity formation, the creation of a salience hierarchy of identities, and commitments to act in accordance with one's identity. Birth mothers have often acted as the most influential significant other in supporting a father's development of a father identity and establishing his commitments to enable relationships with his children (Ihinger-Tallman et al, 1993; Marsiglio, 1994; Stryker, 1968). Relationship supportiveness has also reduced father's parenting stress (Bronte-Tinkew et al., 2010). In addition, having a close connection to one's own father has been a prime motivator for the salience of a father identity and commitments to 
fathering. The relationship has also been a source of social support (Marsiglio \& Roy, 2012;

Palkovitz, 2002). One might expect that family supports may interact with one another in predicting father's parenting stress, such that fathers may report especially low levels of parenting stress when they experience high levels of family support. Also, family supports may not only nurture father's parenting role identities and predict lower levels of stress, but they may also buffer the associations between parenting-relevant stressors and father's parenting stress.

\section{Father-specific, Coparenting, and Child-specific Contextual Factors}

Abidin's (1990; 1992) model of parenting stress recognized a variety of other contextual factors that may lead to parenting stress. Thus, we considered a variety of parenting-relevant stressors as covariates in our models, organized as components of father-specific, coparenting, and child-specific contexts.

Father-specific context. Father-specific contextual factors that may be related to parenting stress include indicators of human capital and instrumental support. Fathers who are older, White, employed, higher earning, well educated, and who can rely on instrumental support were expected to be less likely to experience parenting stress. They may be more mature, not subject to discrimination, established in their careers, and in possession of resources that can allow them to more easily meet the financial and domestic care demands of parenting (BronteTinkew, 2007; Cunningham \& Knoester, 2007; Nomaguchi \& Johnson, 2014; Thoits, 2010).

Coparenting context. Beyond offering an influential and supportive relationship, and an aforementioned dominant influence on father identities, the relationship among coparents may also be reflected, and indirectly influence parenting stress, through living arrangements. That is, men may be more satisfied with fathering roles, encouraged to participate in behaviors that benefit their children, and subjected to more opportunities to parent when they live with the 
coparent and child in an intact family (McLanahan \& Sandefur, 1994; Seltzer, 1991; Townsend, 2002). Conversely, fathering responsibilities are particularly stressful when fathers do not live with the coparent or child (Evenson \& Simon, 2005; Nomaguchi \& Milkie; 2003; Woo \& Raley, 2005). Findings have been mixed about whether something about marriage per se reduces parenting stress relative to simply living in the same household (Bronte-Tinkew et al., 2007; Umberson, Pudrovska, \& Reczek, 2010; Woo \& Raley, 2005). In addition to living together, number of children and household size have also predicted parenting demands (Abidin, 1992; Bronte-Tinkew et al., 2010). Further, birth mother contributions through mother-child engagement and employment have also been linked to parenting stress (Abidin, 1992; BronteTinkew et al., 2010; Knoester et al., 2007).

Child-specific context. Finally, children affect families. A child's negative emotionality may lead to parenting stress (Bronte-Tinkew et al., 2007; McBride, Schoppe, \& Rane, 2002; Umberson, 2010). Also, fathers may view sons as more rewarding and therefore become more engaged with sons than daughters (McBride et al., 2002; Bronte-Tinkew et al., 2007).

\section{Hypotheses}

Father identity theory and previous research suggested four hypotheses about how father identity characteristics are associated with father's parenting stress. In general, we expected that fathers who show more interest, preparation, and fulfillment of parenting roles and responsibilities, with family support, exhibit lower levels of parenting stress.

Hypothesis 1. Indicators of the salience of a father's parenting role- positive attitudes about fatherhood, wanting to provide direct care, and prenatal involvement levels - are negatively associated with his parenting stress one year after the birth of a child. 
Hypothesis 2. Father's commitments that enable relationships with one's child are negatively associated with parenting stress. That is, father engagement was expected to be negatively associated with parenting stress and failing to provide financial support was expected to be positively associated with parenting stress.

Hypothesis 3. Support for father's parenting role identities from significant othersrelationship support from the birth mother and having a highly involved father-is negatively associated with parenting stress.

Hypothesis 4. Father identity characteristics interact with one another in predicting father's parenting stress, such that fathers with more salient parenting role identities, greater commitments that enable relationships with one's child, and support from significant others are especially likely to report lower levels of parenting stress. We anticipate that father identity characteristics also buffer the associations between parenting-relevant stressors and parenting stress.

\section{Method}

\section{Participants}

We used data from the Fragile Families and Child Wellbeing Study (FFCW). The FFCW follows a cohort of new children and their parents beginning in the late 1990s. The sample was designed to be representative of nonmarital births in each of 20 large cities and of all nonmarital births nationally from cities with populations over 200,000 . Thus, the FFCW contains family information from relatively large numbers of cohabiting, single, racial-ethnic minority, and lowincome parents. The demographic characteristics from our sample (shown in Table 1) are in line with the overall FFCW demographic characteristics. Parents were interviewed at the birth of the 
child (either in the hospital or as soon as possible thereafter) and again approximately 12-18 months (Year 1), 3 years (Year 3) and 5 years (Year 5) later.

Approximately 3,700 unwed couples and 1,200 married couples-specifically, 4,898 mothers and 3,830 fathers - were interviewed in the first (Baseline) wave of data collection. Parents from 4,444 families were interviewed in the Year 1 follow-up survey. These included 4,365 mothers $(89 \%)$ and 3,124 fathers $(82 \%)$ who were also interviewed at Baseline. At Year 5 there were approximately $25 \%$ fewer parents remaining in the survey than had begun at Baseline. For additional details about the FFCW study, please refer to Reichman, Teitler, Garfinkel, \& McLanahan (2001).

The initial sample for our study consisted of the 2,547 fathers who were interviewed at both Baseline and Year 1 interviews, who were not in jail during these time periods, and for whom we had data on our measures of interest. The Baseline and Year 1 interviews were especially important for our study because many of the father identity characteristics were only measured at Baseline and parenting stress was first measured at Year 1. We excluded fathers who were incarcerated at Year 1 due to the unique family contexts - and especially challenging stressors - that having a new child while incarcerated presents. Indicators of parenting stress were not measured in the first two cities where interviews were conducted $(n=441)$, but were added to the survey for interviews conducted in the remaining 18 cities.

\section{Measures}

The measures for our study included baseline variables (i.e., measured just after the child's birth and typically time invariant), change over Year 1 variables (i.e., change scores formed from Year 1 value - Baseline value), and time-varying variables over Years 1-5. Many of our measures were commonly used scales that were formed from subsets of questions within 
the Fragile Families Questionnaire (e.g., see Bronte-Tinkew et al., 2003; Knoester et al., 2007; McLanahan \& Carlson, 2003; Nomaguchi \& Johnson, 2014; Reichman et al., 2001). Indeed, the FFCW study expressly sought to achieve high levels of reliability and validity in its measures by drawing from well-established questions that were also used in other surveys (e.g., Early Head Start, Early Childhood Longitudinal Study_-Birth Cohort, etc.). Although we analyzed responses from the same set of closed-ended questions that were asked to all participants in the FFCW study, the data are especially useful for our purposes because they contain an explicit focus on fathers' rights, responsibilities, and behaviors (Reichman et al., 2001). Descriptive statistics for all variables used in the analyses are presented in Table 1.

Dependent variables. Our initial dependent variable was a measure of fathers' parenting stress one year after the arrival of their new child. The scale contained questions from Abidin's Parenting Stress Inventory (Abidin, 1990; 1992). Fathers were presented four statements (Cronbach's $\alpha=.60$ ) about parenting stress: (a) "I feel that taking care of my child(ren) is much more work than pleasure;" (b) "I feel trapped by my responsibilities as a parent," (c) "Being a parent is harder than I thought it would be;" and (d) "I often feel tired, worn out, or exhausted from raising a family." Each Likert-type item had four response options, ranging from strongly disagree (scored 1) to strongly agree (4). The mean response score was used, with higher scores indicating higher levels of parenting stress. In fixed-effects regressions, parenting stress was a time-varying dependent variable drawn from father's Year 1-5 interviews.

Independent variables. Our primary independent variables were father identity characteristics. Indicators of father's parenting salience included time invariant measures that were drawn from the baseline interviews. Responses to three statements $(\alpha=.72)$ at the baseline interview formed a positive attitudes about fatherhood scale. The statements asserted that (a) it 
was fulfilling to be a father and raise children, (b) fathers should want people to know they have a new child, and (c) that not being involved in the life of one's child would be devastating. Response options for each item ranged from strongly disagree (1) to strongly agree (4), and mean scores were calculated; higher scores corresponded with fathers having more parenting salience. Father's interest in providing direct care to their new baby was a dummy variable that indicates whether providing direct care to their new baby was self-rated as very important to them. Prenatal involvement was formed from father's baseline responses (no [0] or yes [1]) to six questions $(\alpha=.52)$ focused on whether the baby will have the father's last name (or whether the father wanted the baby to have his last name); whether the father's name will be on the birth certificate (or whether the father wanted to have his name on the birth certificate); whether the father was present at the birth; held the baby; gave the birth mother money during the pregnancy to buy things for the baby; and whether the father helped in other ways during the pregnancy, such as providing transportation or helping with chores. Response scores were summed, and higher scores indicated more prenatal involvement.

Father's commitments that enabled relationships with his child included time-varying measures of father engagement and financial support. Both measures were initially available at Year 1 and are thus drawn from Year $1-5$ reports. Six activities $(\alpha=.69)$ were used to form scales of positive engagement (e.g., play games, sing songs, read stories to child, etc.). Responses ranged from 0 to 7 days a week and the mean response was used as the scale score. Inconsistent financial support denoted that fathers did not pay child support every time it was due, regardless of whether they had a formal or informal agreement to pay.

Variables that reflected interaction and support from significant others were support from the birth mother and involvement with one's own father. Support from the birth mother was a 
time-varying variable that was constructed from responses to four statements about the birth mother $(\alpha=.59)$ : (a) "She was fair and willing to compromise when you had a disagreement," (b) "She expressed affection or love for you," (c) "She insulted or criticized you or your ideas" (reverse coded), and (d) "She encouraged or helped you to do things that were important to you." Response options for each item ranged from never (1) to often (3); the mean response score was used as the scale score, and higher scores represented more support. We also used a change score variable of support from the birth mother by subtracting the mean support score at the baseline survey from the same at Year 1. Own father's involvement was a time invariant measure that consisted of father's baseline reports of how involved his own father was in his life, with response options ranging from never knew him (0) to very involved (3).

Father-specific context covariates. Father characteristics included human capital and social support indicators. Age, race-ethnicity, economic status, and education were human capital measures. Race-ethnicity was time invariant and was coded into three categories: Black, Hispanic, or non-Hispanic White plus all others (reference category). Annual household income (in $\$ 10,000$ s) and whether the father was unemployed were time-varying and were used to reflect economic status at each interview. Change scores (Year 1 value - Baseline value) were also created for these economic indicators and they measured changes in household income, whether a father became unemployed, and whether a father became employed after previously being unemployed. Father's education consisted of a series of dummy variables that represented his highest level of attainment: less than a high school diploma (reference category), high school diploma or equivalent, some college or technical school, or bachelor's degree or higher. Whether a father was in jail was a time-varying indicator over Years 1-5. 
Instrumental support variables were time-varying measures of available aid from friends or family. Fathers reported at each interview whether they could count on someone to help them by (a) providing a $\$ 200$ loan, and (b) offering them a place to live.

Coparenting context covariates. Coparenting contextual variables reflected family structure and the birth mother's behaviors. Baseline co-resident status indicated whether fathers lived with the birth mother and new child. Baseline marital status indicated whether fathers were married to the birth mother. Baseline number of children denoted other biological children of the father. Baseline household size indicated the total number of adults and children living in the same household as the father.

Dummy variables that indicated changes in coparenting context from the baseline survey to Year 1 included transitions to marriage, cohabitation, relationships with someone other than the birth mother, the transition to resident fatherhood, and the transition from resident fatherhood. We also considered changes in household size, and indicators of whether the mother was unemployed one year after the birth and the mother's positive engagement with the child.

Coparenting contextual variables were also time-varying over Years 1-5. These included indicators of whether fathers were married to the birth mother, cohabited with the birth mother, or were romantically involved with the birth mother. The reference category for relationship status was not being romantically involved. Recent breakup referred to the dissolution of a marital or cohabiting relationship since the previous interview. New relationship denoted whether the father had a romantic partner other than the birth mother. Mother engagement, mother's unemployment status, father's residence with the child, household size, and number of children were the remaining time-varying coparenting context variables. 
Child-specific context covariates. Finally, we used child characteristics as predictors of parenting stress. Child's sex denoted whether the new baby was a boy or a girl. Child's negative emotionality was formed from mother reports at Wave 2 of whether the child often fusses and cries, gets upset easily, and reacts strongly when upset $(\alpha=.60)$; response options for each item ranged from not at all (1) to very much (5).

\section{Analytic Strategy}

We began the analysis with a review of the descriptive statistics. To test our hypotheses, we ran regression models in two stages. First, we used ordinary least-squares (OLS) regression to predict father's parenting stress one year after the birth of the new child. Initially, all predictor variables were taken from the baseline survey (i.e., Baseline Measures in Table 1). Next, we added measures of changing circumstances that may be linked to the context of fatherhood and parenting stress over Year 1. These measures were typically change scores (i.e., Year 1 Baseline values) and were listed as change over Year 1 variables in Table 1, except for timevarying measures that were first available at Year 1 (e.g., mother/father engagement). As part of this analysis, we considered the extent to which father identity characteristics interacted with one another in predicting father's parenting stress one year later. Finally, we used fixed-effects regressions of father's parenting stress on time-varying predictors over Years 1-5. As part of this stage in the analysis, we also considered the extent to which father identity characteristics interacted with one another in predicting father's parenting stress. Also, we investigated the extent to which father identity characteristics buffered the associations between parentingrelevant stressors and parenting stress.

We used STATA 14 for our analyses. Reported results employed multiple imputation with chained equations over 20 imputed data sets. This is a preferred approach in statistical 
analyses because it uses information that respondents provided to predict the likely responses when there is missing data. (Johnson \& Young, 2011).Nevertheless, sensitivity analyses with listwise deletion of missing data produced similar results.

\section{Results}

\section{Descriptive Statistics}

As shown in Table 1, fathers in our sample were disproportionately Black (46\%) or Hispanic (25\%), not highly educated (64\% had a high school degree or less), and $70 \%$ were not married to the birth mother but over $70 \%$ resided with the birth mother and new child at the time of birth. Fathers reported generally high levels of positive attitudes about fatherhood $(M=3.74)$, beliefs about the importance of providing direct care to their new child $(M=0.92)$, and prenatal involvement $(M=5.61)$. Fathers also reported high levels of support from the birth mothers $(M$ $=2.65)$.

One year after birth, fathers reported high levels of father-child engagement $(M=4.30)$ and few (6\%) reported inconsistent financial support. The mean level of parenting stress one year after the child's birth was somewhat low among fathers $(M=2.05)$, indicating that most fathers enjoyed taking care of their children and were not overwhelmed by their parenting responsibilities. Nonetheless, fathers who reported levels of parenting stress that were one standard deviation or more above the mean generally agreed with statements that declared that parenting responsibilities are usually stressful.

\section{Father's Parenting Stress One Year after Childbirth}

As shown in Model 1 of Table 2, fathers who initially held more positive attitudes about fatherhood $(b=-.14, p<.001)$ and viewed the provision of direct care as especially important $(b$ 
$=-.11, p=.023$ reported low levels of parenting stress at Year 1. Support from the birth mother also appeared to be a protective factor $(b=-.15, p<.001)$ for parenting stress.

Other father and coparenting contextual variables were also statistically associated with father's parenting stress. Some college education $(b=-.14, p=.001)$ was negatively associated with father's parenting stress, and larger households $(b=.03, p=.005)$ were associated with a higher risk of parenting stress. Unexpectedly, Black $(b=-.09, p=.013)$ and Hispanic $(b=-.14, p$ $<.001)$ fathers were less likely to report parenting stress than fathers whose race-ethnicity was classified as White/Other. Yet, this finding only emerged after statistically controlling for multiple indicators of human capital (e.g., age, education, unemployment status, etc.). In other words, Black and Hispanic fathers were only less likely to report parenting stress than White/Other fathers when they had equal amounts of human capital.

In Model 2 of Table 2, changes in the fatherhood context over the first year after child's birth were added to the equation. Father identity indicators from Baseline continued to be statistical predictors of parenting stress. In addition, evidence emerged that increases in support from the birth mother $(b=-.13, p<.001)$ were negatively associated with parenting stress. Father's positive engagement $(b=-.03, p<.001)$ was negatively associated with parenting stress, and failing to provide financial support when an agreement to provide support was in place $(b=.14, p=.024)$ was associated with heightened parenting stress.

New parenting-relevant stressor variables also emerged as statistical predictors in Model 2 of Table 2. Becoming unemployed $(b=.11, p=.014)$, transitioning to a resident father $(b=$ $.13, p=.037)$, and birth mother's positive engagement $(b=-.03, p=.016)$ predicted parenting stress. 
Finally, we considered potential interaction effects between father identity characteristics in predicting father's parenting stress at Year 1. As shown in Model 3 of Table 2, we found evidence that positive attitudes about fatherhood interacted with birth mother's support in predicting father's parenting stress. As shown in Figure 1, we graphed this interaction using low (i.e., 1 SD less than the mean), medium (i.e., mean), and high (i.e., $1 \mathrm{SD}$ above the mean) levels of the interacting variables, included the intercept from Model 3, and set all other variables in the model to their mean values. Among fathers who had generally positive attitudes about fatherhood (i.e., support for the importance of fatherhood at mean levels and 1 SD above the mean-all reflecting "agreement" with the importance of fatherhood), higher levels of support from the birth mother moderated the association with parenting stress one year after birth, such that fathers with more uniformly strong agreement in the importance of fatherhood and higher levels of birth mother support had markedly lower levels of parenting stress one year after birth.

\section{Fixed-Effects Regression of Parenting Stress in Child's Years 1-5}

Our fixed-effects regressions of parenting stress over Years 1-5 are shown in Table 3. As indicated in Model 1 of Table 3, changes in father engagement $(b=-.02, p=.047)$ and providing inconsistent financial support $(b=.10, p=.026)$ predicted changes in father's parenting stress.

Changes in parenting-relevant stressors were also associated with changes in father's parenting stress. Having more children $(b=.06, p<.001)$ was positively associated with father's parenting stress. Having the instrumental support of a loan become available $(b=-.08, p$ $=.039$ ) was negatively associated with father's parenting stress. Father's parenting stress also appeared to became markedly lower once a child turned five years old $(b=-.08, p<.001)$.

Finally, as shown in Model 2 of Table 3, there was evidence of an interaction effect. Prenatal involvement moderated father's unemployment status such that becoming unemployed 
was positively associated with changes in parenting stress only among fathers who were very involved in preparing for the birth $(6 \times .16=.96-.86=$ positive slope $)$. In contrast (with a negative slope for change into unemployment), moving into employment was associated with increases in parenting stress for fathers who had not been very involved in preparing for the birth.

\section{Discussion}

In sum, the results of our study provided substantial support for our hypotheses. In addition, they bolstered previous research that documented the excitement and yearning that often surrounds fatherhood, the importance of context in determining how children influence father well-being, the ability to rework father identities, and the complexities for how salient father identities matter. Overall, the results further support attempts to strengthen father identities and commitments to children — and endeavors that seek to encourage these emphases.

First, consistent with identity theory expectations (Ihinger-Tallman et al., 1993; Rane \& McBride, 2000; Stryker, 1968), indicators of the salience of father's parenting role identities appeared to be important predictors of parenting stress, as we hypothesized. Fathers who had more positive attitudes about fathering and wanted to provide direct care to their children reported lower levels of parenting stress at Year 1. Also, fathers who seemed to relish the status and roles associated with fatherhood were less likely to become aggravated by them.

Second, there was consistent support for our hypothesis that father's commitments that enabled a relationship with his child were negatively associated with parenting stress. There was a negative association between father engagement and parenting stress both in our OLS and fixed-effects models. Also, there was a positive association between inconsistent financial support and parenting stress in both the OLS and fixed-effects models. Commitments to one's 
child appeared to reduce father's parenting stress, perhaps because he could appreciate the social bonds that were formed with his child and take satisfaction in fulfilling fathering expectations.

Third, there was some evidence for our expectation that support from significant others was negatively associated with parenting stress. In the OLS models, supportiveness at birth and change in the birth mother's support were negatively associated with father's parenting stress. Change in the birth mother's support was not linked to change in father's parenting stress within individuals throughout Years 1-5 in the fixed-effects models. As relationships changed, children aged, multi-partner fertility occurred, and fathers became more established in particular father identities, support from the birth mother may not have been as influential in determining parenting stress.

Finally, we found modest support for our expectation that father identity characteristics interacted with one another, and with parenting-relevant stressors, in predicting father's parenting stress. At Year 1, fathers experienced especially low levels of parenting stress when they had positive attitudes about fatherhood and they received high levels of support from the birth mother. Also, changes in father's unemployment status and changes in parenting stress over Years 1-5 appeared to depend on father's prenatal involvement. Specifically, becoming unemployed was only associated with increases in parenting stress for fathers who had exhibited very high levels of prenatal involvement. For fathers who had not been involved very much prenatally, transitioning into employment appeared to elevate parenting stress-presumably, entering the labor force was stressful to family relations. Thus, breadwinning (or the absence of it) seemed to both increase and decrease parenting stress, depending on the context.

Beyond a focus on our hypotheses, our results also supported other themes from previous research that analyzed the development of father identities and parenting stress. Our descriptive 
results were consistent with prior work that indicated that fathers become generally excited about the birth of a new child, yearn to fulfill fathering responsibilities, and begin to enact fathering work. Also, they are not overcome with parenting stress, typically; although, some fathers generally agreed that parenting responsibilities were usually stressful (Bronte-Tinkew et al., 2007; 2009; Edin \& Nelson, 2013; Marsiglio \& Roy, 2013; Nomaguchi \& Johnson, 2014).

Second, our findings intersected with the body of research that has emphasized how context largely determines the effects that children have on fathers' feelings of well-being (Evenson \& Simon, 2005; Umberson et al., 2010). Our findings were consistent with research that reported positive associations between valuing fatherhood, commitments to fulfilling fathering roles, relationship quality with the birth mother, and men's feelings of well-being. We also found evidence consistent with the notion that young children are especially difficult: father's parenting stress declined in Year 5 and each additional child between Years 1-5 increased parenting stress. Finally, our results regarding fathers' human and social capital predicting parenting stress also provided support for concerns about how disadvantage may increase parenting stress (Bronte-Tinkew et al., 2007; Bronte-Tinkew et al., 2009; Eggebeen \& Knoester, 2001; Knoester et al., 2007).

Third, our conceptual framework and results indicated that father identities and family processes were works in progress. Father identities, fathering behaviors, support from significant others, and corresponding parenting stresses could be improved over the life course. These findings are supported by previous research (e.g., Edin \& Nelson, 2013; Marsiglio \& Roy, 2012).

Finally, our results hinted at additional complexities in how father identity characteristics may shape fathering experiences, and their consequences. For example, our hypotheses stemmed from assumptions that more salient, committed, and supported parenting role identities would 
lead to lower levels of father's parenting stress. These assumptions appeared to generally be supported. Yet, we did uncover interaction effects that indicated that more salient parenting role identities could also lead to more stressful experiences, such as when fathers become unemployed. Conversely, the interaction that involved positive father attitudes and birth mother support also hinted that fathers may experience lower levels of parenting stress, in some instances (i.e., > $1 \mathrm{SD}$ below mean), if they disengage, or are released, from a parenting situation. In sum, the meaning, importance, and consequences of father identity characteristics deserve more intense scrutiny in future research.

\section{Implications}

Altogether, the results of this study suggest policies and best practices that may help to improve fathering behaviors and the lives of families. We found empirical reasons to encourage and support the formation of salient father identities and commitments that enable fathers' relationships with their children - even beyond the benefits that salient father identities and fathering commitments provide for coparents and children. That is, fathers generally experienced lower levels of parenting stress when they showed more interest, preparation, and fulfillment of parenting roles and responsibilities, with family support.

Therefore, fathers should be encouraged and supported in developing more salient father identities and fathering commitments by significant others, family practitioners, and public policies. More generous family leave — and especially paternity leave_policies, family-friendly workplaces, jobs with livable wages, and legislation and encouragement of shared parenting arrangements could be especially helpful in this regard (Heilman et al., 2016). Relatedly, general practices can be more readily encouraged, and perhaps enhanced, if we better recognized that fathers are typically enthusiastic about the arrival of a new child and often have high aspirations 
for their subsequent fathering behaviors. These emotions and intentions can be built upon. Also, building and supporting salient father identities and strong commitments that enable relationships with one's child(ren) could be better realized if we recognize that father identities are continual works in progress. That is, identities can continually be (re)shaped and commitments can be improved.

\section{Limitations and Future Directions}

Nonetheless, it is also important to recognize the limitations of this study. In our conceptual framework, we viewed the predictors of parenting stress to be similar among new and experienced fathers and among resident and nonresident fathers. In sensitivity analyses, we segregated these groups of fathers and tested for interaction effects involving fatherhood experience and resident status in predicting parenting stress. The results reinforced our inclination to pool these groups of fathers together. Future work should also continue to explore the relationships between fathers' parenting role identities, parenting-relevant stressors, and parenting stress among fathers that may have access to additional sources of social capital and support than was the case with those in our relatively disadvantaged sample.

In addition, our study was limited by a lack of time-varying indicators of the salience of father's parenting role identities. Also, there was not a baseline measure of parenting stress to allow us to consider changes in parenting stress from the birth of a new child to one year later. Finally, it is important to acknowledge that a portion of the relationships between commitments to one's child, support from the birth mother, and parenting stress may be due to reciprocal effects. Yet, based on previous research, our consideration of parenting stress as a dependent variable was warranted (e.g., Knoester et. al, 2007; McBride et al., 2002; Schindler, 2010). 


\section{Conclusion}

This study built upon previous work by more comprehensively analyzing disadvantaged fathers' parenting stress in a national sample and over the first five years of their new child's life. Previous studies have established that there are disparities in men's abilities to live up to the standards of the "new fatherhood" ideal due to variations in parenting contexts (Doeherty et al., 1998; Marsiglio et al., 2000; McLanahan, 2004; Pleck \& Masciadrelli, 2003), and also that these fathering contexts may predict parenting stress among fathers (Bronte-Tinkew et al., 2007). The present study emphasized that father identity characteristics remained statistical predictors of parenting stress, even after accounting for the influence of parenting-relevant stressors that reflected human and social capital, and included indicators of family structure. Thus, the encouragement for men to develop salient parenting role identities, commitments to enable relationships with one's child, and support for the formation of parenting role identities from significant others, might result in not only greater participation in parenting activities, as previous research has shown (e.g., Marsiglio \& Roy, 2012; Rane \& McBride, 2000), but also lower levels of parenting stress. Future work should continue to improve our understanding of how fathers view, form, and respond to their perceptions of responsible fathering. In addition, it is important to trace the consequences of these perceptions and behaviors for men, their children, their coparents, and the rest of society. 


\section{References}

Abidin, R. R. (1990). Introduction to the special issued: The stresses of parenting. Journal of Clinical Child Psychology, 19, 298-301. doi:10.1207/s15374424jccp1904_1

Abidin, R. R. (1992). The determinants of parenting behavior. Journal of Clinical Child Psychology, 21, 407-412. doi:10.1207/s15374424jccp2104_12

Allison, P. D. (2009) Fixed effects regression models. Thousand Oaks, CA: Sage.

Barnett, R.C., Marshall, N.L., \& Pleck, J.H. (1992). Men's multiple roles and their relationship to men's psychological distress. Journal of Marriage and the Family, 54, 358-367. doi:10.2307/353067

Bronte-Tinkew, J., Horowitz, A., \& Carrano, J. (2010). Aggravation and stress in parenting: Associations with coparenting and father engagement among resident fathers. Journal of Family Issues, 31, 525-555. doi:10.1177/0192513X09340147

Bronte-Tinkew, J., Moore, K. A., Matthews, G., \& Carrano, J. (2007). Symptoms of major depression in a sample of fathers of infants. Journal of Family Issues, 28, 61-99. doi:10.1177/0192513X06293609

Cunningham, A., \& Knoester, C. (2007). Marital status, gender, and parents' psychological wellbeing. Sociological Inquiry, 77, 264-287. doi:10.1111/j.1475-682X.2007.00190.x

Doherty, W. J., Kouneski, E. F., \& Erickson, M. F. (1998). Responsible fathering: An overview and conceptual framework. Journal of Marriage and Family, 60, 277-292. doi: $10.2307 / 353848$

Edin, K., \& Nelson, T. J. (2013). Doing the best I can. Berkeley, CA: University of California Press. 
Eggebeen, D. J. (2002). The changing course of fatherhood: Men's experiences with children in demographic perspective. Journal of Family Issues, 23, 486-506. doi:10.1177/0192513X02023004002

Eggebeen, D. J., \& Knoester, C. (2001). Does fatherhood matter for men? Journal of Marriage and Family, 63, 381-393. doi:10.1111/j.1741-3737.2001.00381.x

Evenson, R. J., \& Simon, R. W. (2005). Clarifying the relationship between parenthood and depression. Journal of Health \& Social Behavior, 46, 341-358. doi:10.1177/002214650504600403

Furstenberg, F. F., Jr., \& Cherlin, A. J. (1991). Divided families. Cambridge, MA: Harvard University Press.

Heilman, B., Cole, G., Matos, K., Hassink, A., Mincy, R., \& Barker, G. (2016). State of America's fathers: A MenCare advocacy publication. Washington, DC: Promundo-US.

Ihinger-Tallman, M., Pasley, K., \& Buehler, C. (1993). Developing a middle-range theory of father involvement postdivorce. Journal of Family Issues, 14, 350-371. doi:10.1177/019251393014004005

Johnson, D. R., \& Young, R. (2011). Toward best practices in analyzing datasets with missing data: Comparisons and recommendations. Journal of Marriage and Family, 73, 926-945. 10.1111/j.1741-3737.2011.00861.x

Knoester, C. (2003). Transition in young adulthood and the relationship between parent and offspring well-being. Social Forces, 81, 1431-1457. doi:10.1353/sof.2003.0063

Knoester, C., Petts, R. J., \& Eggebeen, D. J. (2007). Commitments to fathering and the wellbeing and social participation of new, disadvantaged fathers. Journal of Marriage and Family, 69, 991-1004. doi:10.1111/j.1741-3737.2007.00426.x 
Lamb, M. E., Pleck, J. H., \& Levine, J. A. (1987). The role of the father in child development: The effects of increased paternal involvement. In C. Lewis \& M. O’Brien (Eds.), Reassessing fatherhood: New observations on fathers and the modern family (pp. 109125). London, England: Sage.

Marsiglio, W. (1994). Young nonresident biological fathers. Marriage \& Family Review, 20, 325-348. doi:10.1300/J002v20n03_02-

Marsiglio, W., Amato, P., Day, R., \& Lamb, M. (2000). Scholarship on fatherhood in the 1990s and beyond. Journal of Marriage and Family, 62, 1173-1191. doi:10.1111/j.17413737.2000.01173.x

Marsiglio, W., \& Roy, K. (2012). Nurturing dads: Social initiatives for contemporary fatherhood. New York, NY: Russell Sage Foundation.

McBride, B. A., Schoppe, S. J., \& Rane, T. R. (2002). Child characteristics, parenting stress, and parental involvement: Fathers versus mothers. Journal of Marriage \& Family, 64, 9981011. doi:10.1111/j.1741-3737.2002.00998.x

McLanahan, S. (2004). Diverging destinies: How children are faring under the second demographic transition. Demography, 41, 607-627. doi:10.1353/dem.2004.0033

McLanahan, S., \& Carlson, M. (2003). Fathers in fragile families. In M. Lamb (Ed.), The Role of the father in child development (4th ed., pp. 368-396). Hoboken, NJ: John Wiley \& Sons.

McLanahan, S., \& Sandefur, G. (1994). Growing up with a single parent: What hurts, what helps. Cambridge, MA: Harvard University Press. 
Meadows, S. O. (2009). Family structure and fathers' well-being: Trajectories of mental health and self-rated health. Journal of Health \& Social Behavior, 50, 115-131. doi:10.1177/002214650905000201

Nomaguchi, K., \& Milkie, M. ( 2003). Costs and rewards of children: The effects of becoming a parent on adults' lives. Journal of Marriage and Family, 65, 356-374. doi 0.1111/j.17413737.2003.00356.x

Nomaguchi, K., \& Johnson, W. (2014). Parenting stress among low-income and working-class fathers. Journal of Family Issues, 37, 1535-1557. doi:10.1177/0192513X14560642

Palkovitz, R. (2002). Involved fathering and men's adult development. Mahwah, NJ: Lawrence Erlbaum.

Pleck, J. H., \& Masciadrelli, B. P. (2003). Paternal involvement by U.S. residential fathers: Levels, sources, and consequences. In M. Lamb (Ed.), The role of the father in child development (4th ed., pp. 222-271). Hoboken, NJ: John Wiley \& Sons.

Rane, T. R., \& McBride, B. A. (2000). Identity theory as a guide to understanding fathers' involvement with their children. Journal of Family Issues, 21, 347-366. doi:10.1177/019251300021003004

Reichman, N., Teitler, J., Garfinkel, I., \& McLanahan, S. (2001). Fragile families: Sample and design. Children and Youth Services Review, 23, 303-326.

Schindler, H. S. (2010). The importance of parenting and financial contributions in promoting fathers' psychological health. Journal of Marriage \& Family, 72, 318-332. doi:10.1111/j.1741-3737.2010.00702.x

Seltzer, J. A. (1991). Relationships between fathers and children who live apart: The father's role after separation. Journal of Marriage \& Family, 53, 79-101. doi:10.2307/353135 
Stryker, S. (1968). Identity salience and role performance: The relevance of symbolic interaction theory for family research. Journal of Marriage \& Family, 30, 558-564. doi:10.2307/349494

Tach, L., Mincy, R., \& Edin, K. (2010). Parenting as a “package deal:” Relationships, fertility, and nonresident father involvement among unmarried parents. Demography, 47, 181204. doi:10.1353/dem.0.0096

Thoits, P. A. (2010). Stress and health: Major findings and policy implications. Journal of Health \& Social Behavior, 51, S41-S53. doi:10.1177/0022146510383499

Townsend, N. W. (2002). The package deal: Marriage, work, and fatherhood in men's lives. Philadelphia, PA: Temple University Press.

Umberson, D., Pudrovska, T., \& Reczek, C. (2010). Parenthood, childlessness, and well-being: A life course perspective. Journal of Marriage \& Family, 72, 612-629. doi:10.1111/j.1741-3737.2010.00721.x

Woo, H., \& Raley, R. K. (2005). A small extension to "Costs and rewards of children: The effects of becoming a parent on adults' lives." Journal of Marriage and Family, 67, 216221. doi:10.1111/j.0022-2445.2005.00016.x 
Table 1

Descriptive Statistics of Variables Used in Analyses

\begin{tabular}{|c|c|c|c|c|c|}
\hline Variable & $n$ & $\%$ & Variable & $n$ & $M(S D)$ \\
\hline \multicolumn{6}{|l|}{ Baseline measures } \\
\hline Wants to provide direct care & 2,547 & $92 \%$ & Positive attitudes about fatherhood & 2,543 & $3.74(0.42)$ \\
\hline Race-Ethnicity: Black & 2,547 & $46 \%$ & Prenatal involvement & 2,547 & $5.61(0.78)$ \\
\hline Race-Ethnicity: Hispanic & 2,547 & $25 \%$ & Support from birth mother & 2,534 & $2.65(0.37)$ \\
\hline Race-Ethnicity: non-Hispanic White & 2,547 & $29 \%$ & Own father's involvement & 2,535 & $2.06(0.95)$ \\
\hline Unemployed & 2,547 & $13 \%$ & Age & 2,547 & $28.01(7.14)$ \\
\hline Education: Less than high school & 2,547 & $28 \%$ & Household income & 2,547 & $4.06(3.48)$ \\
\hline Education: High school diploma & 2,547 & $36 \%$ & Household size & 2,514 & $3.37(1.50)$ \\
\hline Education: Some college or technical school & 2,547 & $23 \%$ & Number of children & 2,547 & $1.01(1.14)$ \\
\hline Education: Bachelor's degree or higher & 2,547 & $13 \%$ & & & \\
\hline Place to live, if needed & 2,547 & $90 \%$ & & & \\
\hline Loan available, if needed & 2,547 & $89 \%$ & & & \\
\hline Resides with birth mother and child & 2,547 & $74 \%$ & & & \\
\hline Married to birth mother & 2,547 & $30 \%$ & & & \\
\hline Baby is boy & 2,547 & $52 \%$ & & & \\
\hline \multicolumn{6}{|l|}{ Change over Year $1^{\mathrm{a}}$} \\
\hline Become unemployed & 2,547 & $10 \%$ & Change in income & 2,366 & $0.23(4.22)$ \\
\hline No longer unemployed & 2,547 & $6 \%$ & Change in place to live, if needed & 2,547 & $-0.04(0.39)$ \\
\hline Transition to marriage & 2,547 & $9 \%$ & Change in loan available, if needed & 2,547 & $-0.02(0.36)$ \\
\hline Transition to cohabitation & 2,547 & $10 \%$ & Change in birth mother's support & 2,366 & $-0.14(0.43)$ \\
\hline Transition to new relationship & 2,547 & $4 \%$ & Change in household size & 2,479 & $0.71(1.58)$ \\
\hline Transition to resident father & 2,547 & $11 \%$ & Baby's negative emotionality & 2,489 & $2.77(1.02)$ \\
\hline Transition from resident father & 2,547 & $10 \%$ & & & \\
\hline \multicolumn{6}{|l|}{ Time varying measures ${ }^{b}$} \\
\hline Inconsistent financial support & 2,547 & $6 \%$ & Parenting stress & 2,547 & $2.05(0.67)$ \\
\hline Father unemployed & 2,547 & $16 \%$ & Father engagement & 2,547 & $4.30(1.64)$ \\
\hline Mother unemployed & 2,547 & $39 \%$ & Support from birth mother & 2,378 & $2.53(0.42)$ \\
\hline Father in jail & 2,547 & $0 \%$ & Household income & 2,547 & $4.29(4.78)$ \\
\hline Place to live, if needed & 2,547 & $86 \%$ & Mother engagement & 2,481 & $5.11(1.20)$ \\
\hline Loan available, if needed & 2,547 & $88 \%$ & Household size & 2,510 & $4.09(1.49)$ \\
\hline Relationship: Not romantically involved & 2,547 & $20 \%$ & Number of children & 2,544 & $2.02(1.05)$ \\
\hline Relationship: Married to birth mother & 2,547 & $38 \%$ & & & \\
\hline Relationship: Cohabiting with birth mother & 2,547 & $34 \%$ & & & \\
\hline Relationship: Romantically involved & 2,547 & $8 \%$ & & & \\
\hline Recent breakup & 2,547 & $8 \%$ & & & \\
\hline New relationship & 2,547 & $8 \%$ & & & \\
\hline Father resides with child & 2,547 & $76 \%$ & & & \\
\hline
\end{tabular}

Note. ${ }^{\text {a }}$ Change calculated as Year 1 - baseline value. ${ }^{\mathrm{b}}$ Year 1 values are reported in the Time Varying Measures section. 
Table 2

OLS Regression of Parenting Stress One Year after the Birth of a Child $(\mathrm{N}=2,547)$

\begin{tabular}{|c|c|c|c|c|c|c|c|c|c|c|c|c|c|c|c|}
\hline \multirow[b]{2}{*}{ Variable } & \multicolumn{5}{|c|}{ Model 1} & \multicolumn{5}{|c|}{ Model 2} & \multicolumn{5}{|c|}{ Model 3} \\
\hline & $B$ & $95 \% \mathrm{CI}$ & $\beta$ & $t$ & $p$ & $B$ & $95 \% \mathrm{CI}$ & $\beta$ & $t$ & $p$ & $B$ & $95 \% \mathrm{CI}$ & $\beta$ & $t$ & $p$ \\
\hline \multicolumn{16}{|l|}{ Father Identity Characteristics } \\
\hline Positive attitudes about fatherhood & -0.14 & {$[-0.20,-0.07]$} & -.09 & -4.19 & $<.001$ & -0.13 & {$[-0.20,-0.07]$} & -.08 & -4.04 & $<.001$ & 0.42 & {$[0.05,0.80]$} & -.09 & 2.20 & .028 \\
\hline Wants to provide direct care & -0.11 & {$[-0.21,-0.02]$} & -.05 & -2.28 & .023 & -0.10 & {$[-0.20,-0.01]$} & -.04 & -2.09 & .037 & -0.10 & {$[-0.20,-0.01]$} & -.04 & -2.11 & .035 \\
\hline Prenatal involvement & -0.03 & {$[-0.07,0.00]$} & -.04 & -1.76 & .079 & -0.02 & {$[-0.06,0.02]$} & -.02 & -0.99 & .323 & -0.02 & {$[-0.06,0.01]$} & -.03 & -1.23 & .218 \\
\hline Support from birth mother & -0.15 & {$[-0.22,-0.08]$} & -.08 & -4.01 & $<.001$ & -0.21 & {$[-0.29,-0.12]$} & -.11 & -4.73 & $<.001$ & 0.58 & {$[0.05,1.12]$} & -.12 & 2.13 & .033 \\
\hline Own father's involvement & -0.03 & {$[-0.05,0.00]$} & -.04 & -1.77 & .076 & -0.02 & {$[-0.05,0.01]$} & -.03 & -1.51 & .132 & -0.02 & {$[-0.05,0.01]$} & -.03 & -1.53 & .126 \\
\hline Father engagement & & & & & & -0.03 & {$[-0.05,-0.01]$} & -.08 & -3.49 & $<.001$ & -0.03 & {$[-0.05,-0.02]$} & -.08 & -3.59 & $<.001$ \\
\hline Inconsistent financial support & & & & & & 0.14 & {$[0.02,0.25]$} & .05 & 2.25 & .024 & 0.14 & {$[0.02,0.26]$} & .05 & 2.34 & .019 \\
\hline Change in birth mother's support & & & & & & -0.13 & {$[-0.21,-0.06]$} & -.09 & -3.51 & $<.001$ & -0.13 & {$[-0.20,-0.05]$} & -.08 & -3.33 & .001 \\
\hline \multicolumn{16}{|l|}{ Father-Specific Context } \\
\hline Age & -0.00 & {$[-0.01,0.00]$} & -.04 & -1.71 & .088 & -0.00 & {$[-0.01,0.00]$} & -.04 & -1.84 & .067 & -0.00 & {$[-0.01,0.00]$} & -.05 & -1.86 & .063 \\
\hline Race-Ethnicity: Black ${ }^{\mathrm{a}}$ & -0.09 & {$[-0.16,-0.02]$} & -.07 & -2.49 & .013 & -0.10 & {$[-0.17,-0.03]$} & -.07 & -2.77 & .006 & -0.10 & {$[-0.17,-0.03]$} & -.07 & -2.78 & .005 \\
\hline Race-Ethnicity: Hispanic ${ }^{a}$ & -0.14 & {$[-0.22,-0.06]$} & -.09 & -3.54 & $<.001$ & -0.15 & {$[-0.23,-0.07]$} & -.10 & -3.80 & $<.001$ & -0.15 & {$[-0.23,-0.07]$} & -.10 & -3.82 & $<.001$ \\
\hline Unemployed & 0.05 & {$[-0.03,0.13]$} & .03 & 1.31 & .191 & 0.11 & {$[0.00,0.22]$} & .06 & 2.02 & .044 & 0.10 & {$[-0.00,0.21]$} & .05 & 1.88 & .060 \\
\hline Household income & 0.00 & {$[-0.01,0.01]$} & -.01 & -0.43 & .664 & 0.00 & {$[-0.01,0.01]$} & -.02 & -0.62 & .534 & 0.00 & {$[-0.01,0.01]$} & -.02 & -0.59 & .558 \\
\hline Education: High school diploma ${ }^{\mathrm{b}}$ & -0.06 & {$[-0.12,0.01]$} & -.04 & -1.63 & .102 & -0.05 & {$[-0.11,0.02]$} & -.03 & -1.34 & .180 & -0.03 & {$[-0.11,0.02]$} & -.03 & -1.31 & .192 \\
\hline Education: Some college or technical school & -0.14 & {$[-0.22,-0.06]$} & -.09 & -3.42 & .001 & -0.11 & {$[-0.19,-0.03]$} & -.07 & -2.72 & .007 & -0.11 & {$[-0.19,-0.03]$} & -.07 & -2.75 & .006 \\
\hline Education: Bachelor's degree or higher ${ }^{\mathrm{b}}$ & -0.02 & {$[-0.13,0.09]$} & -.01 & -0.38 & .701 & 0.03 & {$[-0.08,0.14]$} & .02 & 0.55 & .586 & 0.03 & {$[-0.08,0.14]$} & .02 & 0.53 & .593 \\
\hline Place to live, if needed & -0.00 & {$[-0.11,0.10]$} & -.00 & -0.06 & .951 & 0.01 & {$[-0.11,0.14]$} & .01 & 0.21 & .837 & 0.01 & {$[-0.11,0.14]$} & .01 & 0.19 & .848 \\
\hline Loan available, if needed & -0.00 & {$[-0.10,0.10]$} & -.00 & 0.08 & .938 & -0.05 & {$[-0.14,0.10]$} & -.01 & -0.36 & .722 & -0.02 & {$[-0.14,0.10]$} & -.01 & -0.31 & .758 \\
\hline Became unemployed & & & & & & 0.11 & {$[0.02,0.20]$} & .05 & 2.46 & .014 & 0.11 & {$[0.02,0.20]$} & .05 & 2.49 & .013 \\
\hline No longer unemployed & & & & & & -0.11 & {$[-0.25,0.04]$} & -.04 & -1.45 & .147 & -0.10 & {$[-0.24,0.04]$} & -.04 & -1.36 & .174 \\
\hline Change in household income & & & & & & 0.00 & {$[0.00,0.00]$} & -.04 & -1.76 & .079 & 0.00 & {$[0.00,0.00]$} & -.04 & -1.69 & .092 \\
\hline Change in place to live, if needed & & & & & & -0.01 & {$[-0.08,0.09]$} & .00 & 0.19 & .848 & -0.01 & {$[-0.08,0.09]$} & .00 & 0.16 & .875 \\
\hline Change in loan available, if needed & & & & & & -0.06 & {$[-0.14,0.05]$} & -.02 & -0.97 & .331 & -0.04 & {$[-0.13,0.05]$} & -.02 & -0.86 & .388 \\
\hline \multicolumn{16}{|l|}{ Coparenting Context } \\
\hline Resides with birth mother and child & -0.03 & {$[-0.10,0.04]$} & -.02 & -0.97 & .332 & 0.07 & {$[-0.03,0.17]$} & .04 & 1.30 & .194 & 0.07 & {$[-0.03,0.17]$} & .05 & 1.36 & .173 \\
\hline Married to birth mother & 0.02 & {$[-0.06,0.09]$} & .01 & 0.42 & .675 & 0.03 & {$[-0.04,0.10]$} & .02 & 0.79 & .427 & 0.03 & {$[-0.04,0.11]$} & .02 & 0.88 & .376 \\
\hline Number of children & -0.00 & {$[-0.03,0.03]$} & -.00 & -0.06 & .954 & -0.01 & {$[-0.03,0.02]$} & -.01 & -0.38 & .706 & -0.01 & {$[-0.03,0.02]$} & -.01 & -0.44 & .661 \\
\hline Household size & 0.03 & {$[0.01,0.04]$} & .06 & 2.82 & .005 & 0.03 & {$[0.00,0.05]$} & .05 & 2.07 & .038 & 0.02 & {$[0.00,0.05]$} & .05 & 2.02 & .044 \\
\hline Transitioned to marriage ${ }^{c}$ & & & & & & -0.07 & {$[-0.16,0.03]$} & -.03 & -1.29 & .198 & -0.06 & {$[-0.16,0.03]$} & -.03 & -1.27 & .204 \\
\hline Transitioned to cohabitation ${ }^{\mathrm{c}}$ & & & & & & 0.04 & {$[-0.08,0.16]$} & .02 & 0.62 & .536 & 0.04 & {$[-0.08,0.16]$} & .02 & 0.65 & .519 \\
\hline Transitioned to new relationship ${ }^{c}$ & & & & & & -0.08 & {$[-0.19,0.03]$} & -.03 & -1.49 & .136 & -0.07 & {$[-0.18,0.04]$} & -.03 & -1.33 & .184 \\
\hline Mother engagement & & & & & & -0.03 & {$[-0.05,-0.01]$} & -.06 & -2.40 & .016 & -0.03 & {$[-0.05,-0.00]$} & -.05 & -2.33 & .020 \\
\hline Birth mother unemployed & & & & & & 0.03 & {$[-0.03,0.08]$} & .02 & 0.99 & .322 & 0.03 & {$[-0.03,0.08]$} & .02 & 1.01 & .314 \\
\hline Change in household size & & & & & & -0.00 & {$[-0.02,0.02]$} & -.01 & -0.19 & .850 & -0.01 & {$[-0.02,0.02]$} & -.01 & -0.28 & .777 \\
\hline Transitioned to resident fatherhood & & & & & & 0.13 & {$[0.01,0.25]$} & .06 & 2.08 & .037 & 0.13 & {$[0.01,0.25]$} & .06 & 2.12 & .034 \\
\hline Transitioned from resident fatherhood & & & & & & 0.01 & {$[-0.10,0.11]$} & .00 & 0.15 & .885 & 0.00 & {$[-0.10,0.11]$} & .00 & 0.03 & .974 \\
\hline \multicolumn{16}{|l|}{ Child-specific Context } \\
\hline Baby is boy & .02 & {$[-0.03,0.08]$} & .02 & 0.93 & .350 & 0.03 & {$[-0.02,0.08]$} & .02 & 1.18 & .237 & 0.03 & {$[-0.02,0.08]$} & .02 & 1.12 & .263 \\
\hline Baby's negative emotionality & & & & & & 0.01 & {$[-0.02,0.03]$} & .01 & 0.52 & .604 & 0.01 & {$[-0.02,0.03]$} & .01 & 0.62 & .536 \\
\hline \multicolumn{16}{|l|}{ Interactions } \\
\hline Positive attitudes $\mathrm{x}$ & & & & & & & & & & & -0.21 & {$[-0.36,-0.07]$} & -.05 & -2.93 & .003 \\
\hline
\end{tabular}


Support from birth mother

Note. Model $1 R^{2}=.05$, Model $2 R^{2}=.08$, and Model $3 R^{2}=.08$ ( $p<.001$ for all models). CI $=$ confidence interval for $B$. Reference groups are: ${ }^{\text {a }}$ non-Hispanic White/other, ${ }^{b}$ Less than high school, ${ }^{c}$ Remained the same. 
Table 3

Fixed Effects Regression of Parenting Stress in Child's Years 1-5 (N = 2,547)

\begin{tabular}{|c|c|c|c|c|c|c|c|c|c|c|}
\hline \multirow[b]{2}{*}{ Variable } & \multicolumn{5}{|c|}{ Model 1} & \multicolumn{5}{|c|}{ Model 2} \\
\hline & $B$ & $95 \% \mathrm{CI}$ & $\beta$ & $t$ & $p$ & $B$ & $95 \% \mathrm{CI}$ & $\beta$ & $t$ & $p$ \\
\hline \multicolumn{11}{|l|}{ Father Identity } \\
\hline \multicolumn{11}{|l|}{ Characteristics } \\
\hline Father engagement & -0.02 & {$[-0.03,-0.00]$} & -.04 & -1.99 & .047 & -0.02 & {$[-0.03,-0.00]$} & -.04 & -2.08 & .038 \\
\hline Inconsistent financial support & 0.10 & {$[0.01,0.19]$} & .02 & 2.22 & .026 & 0.10 & {$[0.01,0.19]$} & .02 & 2.26 & .024 \\
\hline Support from birth mother & -0.03 & {$[-0.08,0.02]$} & -.02 & -1.12 & .263 & -0.02 & {$[-0.08,0.03]$} & -.02 & -0.90 & .368 \\
\hline \multicolumn{11}{|l|}{ Father-Specific Context } \\
\hline Unemployed & 0.02 & {$[-0.04,0.08]$} & .02 & 0.74 & .459 & -0.86 & {$[-1.26,-0.47]$} & -.47 & -4.30 & $<.001$ \\
\hline Household income & -0.00 & {$[-0.01,0.00]$} & -.01 & -1.27 & .203 & -0.00 & {$[-0.01,0.00]$} & -.02 & -1.28 & .202 \\
\hline In jail & -0.03 & {$[-0.31,0.25]$} & -.01 & -0.21 & .836 & -0.02 & {$[-0.29,0.26]$} & -.00 & -0.11 & .911 \\
\hline Place to live, if needed & -0.01 & {$[-0.07,0.06]$} & -.00 & -0.17 & .866 & -0.00 & {$[-0.07,0.06]$} & -.00 & -0.09 & .927 \\
\hline Loan available, if needed & -0.08 & {$[-0.15,-0.00]$} & -.04 & -2.06 & .039 & -0.08 & {$[-0.15,-0.01]$} & -.04 & -2.12 & .034 \\
\hline \multicolumn{11}{|l|}{ Coparenting Context } \\
\hline Married to birth mother ${ }^{\mathrm{a}}$ & -0.03 & {$[-0.13,0.08]$} & -.03 & -0.52 & .602 & -0.02 & {$[-0.13,0.08]$} & -.03 & -0.43 & 670 \\
\hline Cohabiting with birth mother ${ }^{\mathrm{a}}$ & 0.04 & {$[-0.05,0.14]$} & .02 & 0.89 & .375 & 0.04 & {$[-0.05,0.14]$} & .02 & 0.93 & .353 \\
\hline Romantically involved $^{\mathrm{a}}$ & -0.02 & {$[-0.12,0.07]$} & -.01 & -0.46 & .649 & -0.02 & {$[-0.12,0.07]$} & -.01 & -0.46 & .646 \\
\hline Recent breakup & 0.01 & {$[-0.05,0.07]$} & .00 & 0.38 & .703 & 0.01 & {$[-0.04,0.07]$} & .00 & 0.48 & .630 \\
\hline New relationship & -0.02 & {$[-0.09,0.05]$} & -.01 & -0.43 & .666 & -0.02 & {$[-0.09,0.05]$} & -.01 & -0.46 & .645 \\
\hline Mother engagement & -0.01 & {$[-0.03,0.01]$} & -.02 & -1.30 & .194 & -0.01 & {$[-0.03,0.01]$} & -.02 & -1.27 & .206 \\
\hline Mother unemployed & -0.01 & {$[-0.04,0.03]$} & -.00 & -0.27 & .786 & -0.00 & {$[-0.04,0.04]$} & -.00 & -0.15 & .884 \\
\hline Resides with child & 0.03 & {$[-0.05,0.10]$} & .02 & 0.72 & .472 & 0.02 & {$[-0.05,0.10]$} & .02 & 0.64 & .519 \\
\hline Household size & 0.01 & {$[-0.01,0.02]$} & .02 & 0.98 & .329 & 0.01 & {$[-0.01,0.02]$} & .02 & 0.83 & .409 \\
\hline Number of children & 0.06 & {$[0.03,0.09]$} & .09 & 3.97 & $<.001$ & 0.06 & {$[0.03,0.09]$} & .09 & 3.96 & $<.001$ \\
\hline Year $3^{\mathrm{b}}$ & -0.00 & {$[-0.03,0.03]$} & -.00 & -0.20 & .843 & -0.00 & {$[-0.03,0.03]$} & -.00 & -0.14 & .890 \\
\hline Year $5^{\mathrm{b}}$ & -0.08 & {$[-0.12,-0.04]$} & .01 & -3.83 & $<.001$ & -0.08 & {$[-0.11,-0.04]$} & .01 & -3.80 & $<.001$ \\
\hline \multicolumn{11}{|l|}{ Interactions } \\
\hline $\begin{array}{l}\text { Prenatal involvement } \mathrm{x} \\
\text { unemployed }\end{array}$ & & & & & & 0.16 & {$[0.09,0.23]$} & .49 & 4.56 & $<.001$ \\
\hline
\end{tabular}

Note. Model $1 R^{2}: .02$ (within), .03 (between), .03 (overall). Model $2 R^{2}:=.03$ (within), .02 (between), .03 (overall). $p<.001$ for all models. CI = confidence interval for $B$. Reference groups are: ${ }^{a}$ Not romantically involved, ${ }^{b}$ Year 1. 


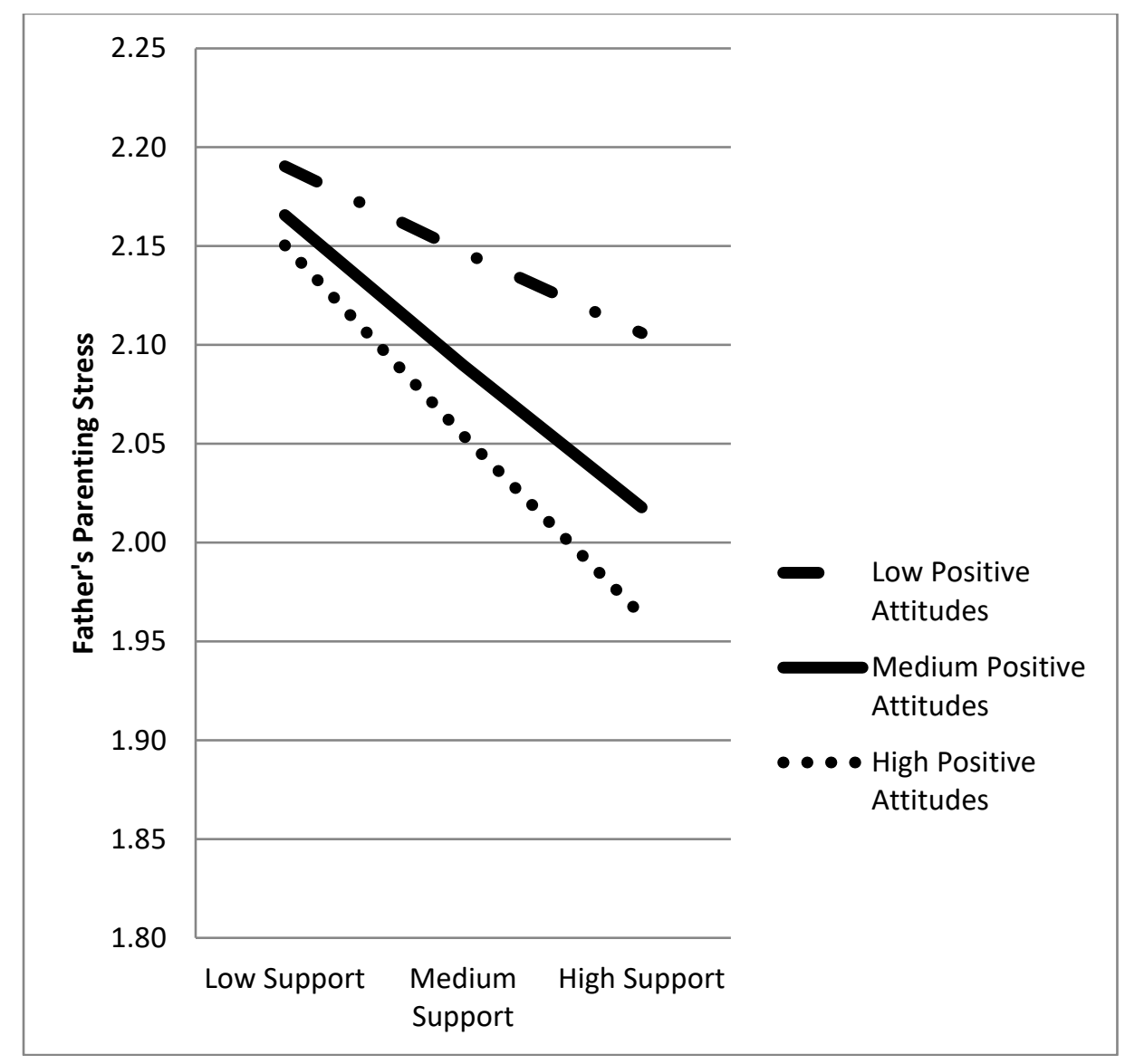

Figure 1. Interaction between positive attitudes about fatherhood and birth mother support in predicting father's parenting stress. 